\title{
Production Footprint Choices
}

Of the sample companies below, about half of them maintained an exclusively, or predominantly, Swiss-based manufacturing footprint. The other researched companies exhibited varying degrees of production delocation-ranging from partial assembly to full production, having a distributed footprint with largely international production or, in a few cases, moving all the way to full offshoring.

\section{Exclusively Swiss-Based Production}

An exclusively Swiss-based production footprint was maintained by 12 out of the 36 companies researched. Exclusively meaning that all production and final assembly steps took place in Switzerland except for material or component purchases of elements not available locally. The majority of these companies were on the lower sales volume range, although several of them belonged to the above CHF 300 million range.

Three companies, that can be considered part of this purist group, are featured below.

DC Swiss operated two manufacturing sites, both in the Jura Bernois. The main site in Malleray produced all finished tools since 1962. In 1990, a second site was opened in nearby Bevillard, taking over an existing building site producing tool blanks only. This allowed a further expansion of manufacturing space for finishing tools in Malleray. Between the two sites, the company produced more than 5,000 tools daily, or about 1 million tools annually. The average net revenue per tool amounted to about CHF 20. DC Swiss had several thousand SKUs, of which most were considered standard. The company operated a modern machine park with many $\mathrm{CNC}$ machines for grinding tools to specifications. Acquiring new production equipment represented some of the major investments beyond building construction. ${ }^{1}$

\footnotetext{
${ }^{1}$ Adapted from DC Swiss company profile. 
Felco's production base was still in Les Geneveys-sur-Coffrane, the same village in the Jura Bernois where the company was originally founded. The site in the central part of the village had been expanded several times to include a number of different and adjacent buildings. The factory produced about 5,000 units of different tools per day. The key aluminium handles were produced by a separate, company owned, producer in the Canton Jura. Eric Perrin, son-in-law of company founder and CEO of Felco from 1974 to 2002, strongly believed in investing in people and keeping local jobs in the Jura region. Aside from some exceptions, no production was moved offshore, such as to China. Some accessories were also sourced abroad. ${ }^{2}$

Caran d'Ache was committed to remain and produce in Switzerland, eliminating the option of moving across the border into nearby France. The label 'Made in Switzerland' required a Swiss production site. With about two thirds of company staff involved in production, finding the right talent was important. In the Geneva region, there was access to talent steeped in manufacturing products from metal, such as for watch making. But for many of the Caran d'Ache processes, staff had to be trained in-house with retention being an important consideration. On average, employees had been with the company about 15 years with some for as many as 40 to 50 years. Although the company participated in apprenticeship programs, for core manufacturing processes only in-house training would suffice as there were no other employers with similar needs in the region. ${ }^{3}$

Management at these smaller companies was conscious of the cost penalty incurred, compared to international competition, by maintaining their production in Switzerland. By engaging in step-by-step automation, they tried to compensate their cost-differential through higher productivity per man-hour. In addition, they believed that they are gaining substantial quality benefits through a specialized and highly trained labor force that more than justifies the Swiss location. Last but not least, by remaining in Switzerland, they were able to use the label Swiss made as a quality symbol, which would justify a premium price in most markets.

Among the larger companies in the sample, Jura, although having outsourced its production, used a Swiss-based contract manufacturer for its entire output, allowing the company to trade under the Swiss made label. Ricola remained attached to its location in Laufen for its entire production. The company's production was organized into two long shifts with most of the employees recruited locally. The efficiency of the production operation, including automation and robots, allowed Ricola to compensate for otherwise higher salary costs compared to neighboring countries. From its inception, Thermoplan had relied on local Swiss suppliers for its components, made to specifications as per Thermoplan engineering designs. At its Swiss base in Weggis (SZ), Thermoplan concentrated on assembly operation and quality assurance, since more than $90 \%$ of its sales went into exports. All three companies had organized their business systems in such a way that they could achieve global competitiveness despite operating from a Swiss base.

\footnotetext{
${ }^{2}$ Adapted from Felco company profile.

${ }^{3}$ Adapted from Caran d'Ache company profile.
} 


\title{
Modified Swiss Manufacturing
}

Although maintaining a mostly Swiss-based manufacturing footprint, some companies found a need to offshore some assembly processes for marketing and cost reasons. These arrangements typically dealt with parts of the product line only. Three firms featured here belong to this category. All of them have their main manufacturing site in Switzerland: Sylvac, EAO, and Pilatus.

Sylvac made different manufacturing arrangements for its own branded line, compared to its OEM branded line which went mostly to Asian distributors.

\begin{abstract}
All products sold under the Sylvac brand name were assembled in Switzerland and the company had no plans to produce in China beyond its OEM business, which was not sold under the Sylvac brand. The China operation near Shanghai had a dual role. First, it was to help with the sourcing of components to be sent to Switzerland. Second, it was as an assembly point for those tools traded through OEM arrangements in the Asian region. Concerning the calipers product line, the company sourced blank calipers abroad and finished them in Switzerland. ${ }^{4}$
\end{abstract}

Mikrop, a leading manufacturer of high-end micro optics, maintained its main production base in Switzerland. However, the relatively high cost of conducting business in Switzerland was regarded as a disadvantage. Labor costs and building costs, for example, were significantly higher than in other European countries. In addition, an extraordinary phase of appreciation of the Swiss currency meant that Mikrop could only benefit to a limited extent from cheaper purchasing prices abroad. To counter the high costs in Switzerland, Mikrop outsourced part of the production to Serbia. This facility was used for the production of standardized, basic products. ${ }^{5}$

EAO maintained a major assembly operation at its main location in Olten where the company also managed sourcing of parts and components. Three assembly points for specific products were maintained in Germany, the USA, and China.

\begin{abstract}
Among its four manufacturing operations, the EAO Swiss plant in Olten was a major assembly point. The operation in Germany carried out the assembly for automotive applications and off-road vehicles. The US assembly operation was geared towards public railways projects where local content was important. China was described as the "work bench' for assembling standard products based largely on imported components, as well as serving local Chinese customers with localized HMI products. ${ }^{6}$
\end{abstract}

Pilatus, the company with the largest Swiss-based manufacturing footprint among the researched companies, had a sizeable workforce of close to 2000 employees on its main site in Stans. Pilatus manufacturing operations had been expanded continuously over the years. Production has gone from 50 units annually around the year 2000 to about 125 units annually today. Half of its employees were involved in manufacturing operations. Planes destined for US delivery were

\footnotetext{
${ }^{4}$ Adapted from Sylvac company profile.

${ }^{5}$ Adapted from Mikrop company profile.

${ }^{6}$ Adapted from EAO company profile.
} 
customized in its Colorado operation in the USA where more than 200 employees, worked mostly on general aviation models.

\section{Swiss and International Production}

About one third of the companies established substantial production capacities outside of Switzerland. The Swiss base remained significant, but for some parts of the business the international production assumed a much greater role than in the previously cited companies. The triggers for the internationalization varied. While some companies were more driven to remain cost-competitive, others followed the demands of their customers, or acquisitions abroad came with production assets. Both Rüeger and Fraisa moved some basic manufacturing operations abroad to Asia and Eastern Europe, respectively, in order to save costs and remain competitive.

At Rüeger, manufacturing of its instruments had always been central to the development of the company. At its plant, Rüeger manufactured core components on the basis of its own temperature measurement technology. Production processes and equipment were designed and built by the company and could not be acquired on the open market. As the company expanded in Asia, final assembly of its instruments was moved into Malaysia, where standard products were also produced. For the pressure gauge segment, products were sourced externally as that market had commoditized and could not be served any longer from the high-cost Swiss base. These policies were reflected in the headcount of the Swiss operation. Whereas employment 20 years ago was 120 , it had now shrunk to about 70 , with about 45 in production.

Fraisa's manufacturing footprint had undergone both expansion and contraction over time, while becoming increasingly globalized. Manufacturing operations at its Bellach plant in Switzerland was now the only production point in Switzerland with two others closed during the crisis years. The operation in Hungary, first started in 2002 and expanded in several steps, comprised more than 150 employees today and produced around 55 percent of Fraisa standard tools. Since the Swiss Franc gained more and more strength over the years, Fraisa's good economic situation had largely to do with the internationalization of its production. ${ }^{8}$

Other than establishing a weaving plant in France in 1911, Sefar did not engage in any large-scale production abroad until the mid-1990s when distributors were acquired, and Asia emerged as a major market. The imbalance between cost accruing in Switzerland and sales taking place abroad was a major issue for the company.

The most important step at Sefar was the construction of a weaving plant in Thailand in 1996, to meet increasing demand in Asia, followed by the establishment of a new weaving plant in Romania in 2007. Following the opening of the production sites in Thailand and Romania, the remaining production sites in France were closed. In 2018, the volume of tissues produced abroad was $40 \%$. However, the majority of weaving machines were still operated in Switzerland. The expansion of production abroad was driven by the objective of

\footnotetext{
${ }^{7}$ Adapted from Rüeger company profile.

${ }^{8}$ Adapted from Fraisa company profile.
} 
reducing the imbalance between the country generating the largest portion of costs (Switzerland), and the countries generating yields. Even in 2018, only 2-3 percent of its sales volume came from Sefar's Swiss customers while more than half of the costs was accrued there. This mismatch had become a great challenge when the Swiss Franc began to appreciate strongly in the 1970 s, and even more so later on. ${ }^{9}$

The experiences of Sécheron and Burckhardt Compression were based upon shifting component manufacturing and assembly for their entire operations, but in opposite directions. On the one hand, Sécheron moved parts of their manufacturing to Eastern Europe but assembled at its Swiss site in Geneva. Burckhardt, on the other hand, acquired local assembly operations abroad and supplied them with key components, amounting to about $80 \%$ of the final product. Sourcing the rest locally, plus saving on assembly labor costs, made the final product more competitive.

At Sécheron, the Geneva site continued to be used for final assembly and testing of components, as well as research. This meant that customers took ownership of products in Geneva, projecting the Swiss Company and Swiss made image. Head count there varied, ranging from around 240 to 280. Major changes took place in Sécheron's Prague components manufacturing operation. At the time of starting the turnaround in Geneva, the new owners realized that they also had to accomplish a turnaround in Prague. The operation there, formerly a site under Communist control, needed to be moved into a Western-style performance culture with the infusion of young people. The operation in Prague was brought to a European level in terms of costs, even while currency values moved substantially. Starting out with a workforce of 230, the Prague operation first declined to about 170 and then grew back to $550 .^{10}$

By the end of WWII, employment at the Burckhardt factory in Basel and other locations topped 500, a number that stayed constant until the business was merged into the Sulzer Group. This merger brought about the consolidation of all manufacturing activities in Oberwinterthur where employment amounted to about 330 persons at the time of the MBO, with another 100 in international operations abroad. About 80 percent of all manufacturing took place in Oberwinterthur. Burckhardt was able to acquire the compressor business in India run by Sulzer Group in 2005. Additional assembly facilities were opened in Korea in 2015 in the vicinity of a shipbuilding cluster, as well as in Waller, Texas, to assemble compressors destined for the North American market and for customers where local assembly was important. The US plant sourced the critical components from Switzerland, and the rest, about two thirds, from US suppliers. Through the acquisition of the leading Chinese piston compressor manufacturer, Burckhardt gained access to the Chinese local market through assembly of its own compressors and as a sourcing point for components to be used in its Swiss and US assembly plants. ${ }^{11}$

Acquisitions led to additional manufacturing assets for some companies. Filtrox acquired the operation of a smaller competitor in the UK, then entered the Czech market through a joint venture, and finally acquired a filter producer in Mexico to

\footnotetext{
${ }^{9}$ Adapted from Sefar company profile.

${ }^{10}$ Adapted from Sécheron company profile.

${ }^{11}$ Adapted from Burckhardt company profile.
} 
supply the US market. The result of these acquisitions was a shift of employment toward the foreign operations.

Major customers can also have an impact on the manufacturing footprint as the experience of Plaston demonstrates. Two of its major customers for plastic packaging systems drove Plaston to localize production in Eastern Europe and in China, posing considerable challenges for a medium-sized company.

In 1985, Bosch became Plaston's second key account for packaging systems, after Hilti. In the early 1990s, Bosch inquired if Plaston would consider producing the cases closer to its factory near the Czech border. The project in Sluknov rapidly took shape. Plaston acquired an existing $5,000 \mathrm{~m}^{2}$ production facility in 1995 and soon began to produce their first cases. To this day, this plant has continuously operated production in three shifts. ${ }^{12}$

The decision to produce in the Czech Republic strengthened the relationship with Bosch. Building electrical appliances involved considerable assembly work, and the Sluknov location offered both a qualified and cost-competitive labor force. Lower manufacturing costs, combined with items purchased in Eastern Europe, allowed Plaston to establish a foothold for its Boneco air treatment products in the competitive US market.

The experience of the companies that expanded their production footprints abroad demonstrated that this was done either to protect the cost competitiveness of their business or to hang on to key customer relationships, leading to additional business. In general, the Swiss production base remained intact although it did not grow as additional workforce growth took place abroad. In all cases, the success of international expansion contributed to the health and sustainability of the Swiss production base.

\section{Globally Distributed Production}

A few of the larger SMEs surveyed moved beyond their Swiss production base to build true global networks, with varying roles for the Swiss home base. These companies had sales in the range of CHF 200-500 million. Typically, they built production networks with distributed production mandates, usually specializing on parts of their product line, or they created supply networks in the vicinity of a global customer base.

LNS, the producer of machine tool peripherals such as bar feeders, grew from a single-site operation in Switzerland through acquisitions of manufacturers of other peripherals that were then integrated into a coherent international sales strategy.

At LNS, the establishment of Japanese, Taiwanese and Chinese manufacturing centers, and the acquisition of Turbo Systems in the US, led to a complete realignment of manufacturing mandates through the LNS group of companies. The supply strategy was based on

\footnotetext{
${ }^{12}$ Adapted from Plaston company profile.
} 
manufacturing in three regions, with the Asian production centers concentrating on supplying Asian markets; the US, with a staff of 150 across two production sites, on North America; and, the European factories in the UK, Italy and Switzerland concentrating on supplying European customers. At the Swiss site, the regionalization strategy impacted on staffing levels. Employment dropped from a maximum of 130 to about 80 employees now. For production staff alone, employment dropped from a onetime high of 100 to about 30 as the Swiss site concentrated on the assembly of the advanced bar feeder systems with some parts supplied from the Chinese operation. Overall, the Swiss site produced only about 10 percent of the LNS Group revenue. Engineering activities for bar feeders were carried out in Switzerland, Taiwan and the US. Since the key elements of engineering and design were concentrated in Switzerland, LNS traded under a Swiss Engineering label. ${ }^{13}$

Although Komax, the supplier of cabling systems, also pursued a strategy of assembling a number of peripheral equipment, similar to LNS, the impact on the Swiss manufacturing base was not negative and did not hinder Swiss employment growth while the production site experienced continued expansion.

\begin{abstract}
Komax operated 19 production sites of different size, mandates and tasks. By far the largest production site was its Swiss plant in Dierikon (LU), subject to a major CHF 70 million expansion for 2019-2020 and was the center for standard equipment and systems. Sites in Germany focused on customized equipment or systems, such as for solutions and clientspecific systems, for taping and for testing equipment. The site in Hungary concentrated on development and production of solutions of high voltage cables for electric mobility. The operation in Japan was dedicated to benchtop machines and the China operations were mainly for the Asian market. Other production points were for engineering and assembly of testing systems for the local markets. These sites were located in countries where wire production was concentrated, such as Turkey, Bulgaria, Rumania, Mexico, Brazil, Tunisia and Morocco. ${ }^{14}$
\end{abstract}

What separated Komax from LNS was that Komax did not move Swiss-based manufacturing mandates to new acquisitions abroad which manufactured new and different elements not made at the main site in Switzerland. A different strategy was again pursued by Bachem, where production mandates were assigned to different locations on the basis of regulatory approvals and geographic market assignments.

Although Bachem covered the world market with its product supply, manufacturing was concentrated at six locations in Europe and North America that also doubled as development and marketing locations. Production of chemical substances ranged from milligram amounts for pre-clinical work to tons for of active pharmaceutical ingredients (API) or key intermediates. Equally, the company possessed capacity to produce small molecule generics and new chemical entities (NCE) in multiple tons. By far the largest production site was in Switzerland (Bubendorf) where Bachem has produced since 1971. Production API was current good manufacturing facility (cGMP) approved by the US Food and Drug Administration (FDA), allowing for shipments to many countries and into the important US market. The Bubendorf site also produced research products listed in the Bachem catalog and was approved by the Japanese Ministry of Health for deliveries to Japan. A second Swiss site in Vionnaz focused on APIs and complex organic molecules. The two sites in the United States

\footnotetext{
${ }^{13}$ Adapted from LNS company profile.

${ }^{14}$ Adapted from Komax company profile.
} 
were also FDA approved for cGMP and one site was approved for deliveries to Japan. The UK site concentrated on producing non-cGMP research products. ${ }^{15}$

Two companies, Oetiker and maxon, had adopted strategies of exporting entire product lines, or parts thereof, with different impact on their main Swiss sites. In the case of Oetiker, the strategy led to a slimmed-down production of key elements needed by international sites, whereas maxon duplicated parts of its production elsewhere for capacity growth but continued to maintain its Swiss production volume and employment. "maxon does not transfer production, we duplicate it elsewhere," Eugen Elmiger, CEO maxon has said.

maxon maintained its largest production and development base in Sachseln (OW), employing about half of its global workforce. The Swiss operation engaged in all manufacturing activities, including assembly, for which the company also employed some home workers in the region, mostly women who tended to have higher manual dexterity than men. The Swiss operation also tested assembly and production lines before they were added to overseas plants. As maxon grew in headcount at its Swiss plant, so did the difficulty of hiring staff. The Canton of Obwalden (OW) offered only a small labor pool and with a lack of expansion capability the company risked having to extend delivery times and losing flexibility. In response to this growing trend, maxon decided to open a manufacturing plant in Sexau, near Freiburg in Germany, with concentration on gears. The gears were first developed and designed in Switzerland and then transferred for production to Sexau. With expanding volume, the business unit for mechatronics and dental applications were also concentrated in Sexau.

The mentality in the Schwarzwald region of Southern Germany is similar to Switzerland, making collaboration and integration of operations easier (Elmiger, CEO). ${ }^{16}$

While maxon's first move abroad was driven by a limited labor pool in Switzerland, later moves were a response to cost pressures as a result of Swiss currency appreciation that led to open manufacturing operations first in Hungary and later in Korea. It is notable how maxon compares costs between its different manufacturing operations, using the concept of and not cost per man-hour as in some other companies.

In comparison to maxon's operation in Switzerland, wage costs in Hungary were about one-fifth while at the same time offering a sufficiently trained labor pool to recruit and build an operation. Starting small in 2001 with just a small team, the operation was expanded in several steps to account for a labor force of several hundred. The Hungarian plant engaged in production and assembly. Without access to the latest in winding technology. Growing business in Korea led to the creation of a production unit there as well. Growing out of a successful distribution business, the Korean operation began with the production of brushless motors as winding around iron was easier to accomplish. Later, a robotics operation for iron cores was added in 2013. On a comparative basis, labor costs in Korea were about one-quarter of the Swiss level. Despite the wage level differences, the Swiss

\footnotetext{
${ }^{15}$ Adapted from Bachem company profile.

${ }^{16}$ Adapted from maxon company profile.
} 
operation was still competitive on the basis of profit-per-person, the key operating metric used at maxon. ${ }^{17}$

Oetiker Group adopted a different strategy. When the research team visited the company, they were received by Thomas Meier-Bickel, CEO and grandson of the founder, with the comment: "We are not a typical export company." The company operated 12 foreign production operations, each with a number of production lines. Since most production took place in the currency areas of Oetiker's customers, the distributed number of plants worked as a hedge against currency fluctuations centering around the ever-appreciating Swiss Franc.

At Oetiker's head office location in Horgen (ZH), staffing was about 110 out of the global headcount of almost 1,900. Production activity in Horgen focused on core stamping tools needed for the 12 foreign production operations. Key tools were needed for the stamping operations, assembly tools and critical components for production machinery placed in the various foreign production operations. Production equipment was proprietary and engineered or adapted by Oetiker for its own needs. Most production plants were for clamps and a few were also producing tools needed to apply the clamps in assembly operations of Oetiker clients. Production was organized around process lines per product and the various production operations contained a different number of such process lines. The size of the production operations ranged from 70 employees for the smallest unit to 350 employees for the largest unit. ${ }^{18}$

Typically, the clamp operations were located near clusters of customers, the tier automotive suppliers. Main production centers were located in Europe (Germany, Spain, Sweden, Lithuania and Poland), in North America (US and Canada for four plants in total) and Asia with plants in China and India. The production centers all produced the most common clamps or lead products and some specialty clamps were produced in selective locations only according to local customer requirements. ${ }^{19}$

For Oetiker, its tier automotive customers required production in the vicinity of their assembly operations, thus making exporting from the Swiss home base logistically impracticable. The added benefit of such a distributed production footprint was the currency hedge against the continually appreciating Swiss Franc.

LEM, the Geneva-based electricity measurement company, also maintained a global manufacturing footprint similar to Oetiker. Since the company manufactured its components for a large number of clients, the company could concentrate its manufacturing in fewer places. Similar to Oetiker, its workforce in Geneva is small compared to the global total but, in contrast, had remained stable over time, albeit with a changing composition in skills and functions.

The largest concentration of LEM employees was in China with a workforce of about 900 . China was first and important market for LEM, also turning into an important production point. China was rapidly becoming the largest single market for LEM with about one third of

\footnotetext{
${ }^{17}$ Ibid.

${ }^{18}$ Adapted from Oetiker company profile.

${ }^{19} \mathrm{ibd}$.
} 
sales. More than half of LEM's production capacity was now in China. In Europe, the largest production center was in Bulgaria with about 260 employees. The Bulgaria expansion was both a response to bring the Euro-denominated sales and production in balance, as well as leverage the local technical university in Sofia for engineering talent. In the US, LEM maintained a customization hub to adapt modules to US standards in terms of software, cables, and other interfaces. Japan was still a small production base focusing on local product specialties as well as on sales to Japanese customers. ${ }^{20}$

As a volume manufacturer of high-quality products, LEM produced on automated production lines combined with skilled assembly and testing. Although the company did not divulge production volumes, outsiders have estimated the output at more than 60 million units. In line with the evolution of LEM sales, its manufacturing set-up changed. When the company commenced operation in 1972, everything was Geneva-focused. With the founders' strong ties to the local community and government, relocating operations was not a consideration. However, given the increasing price pressure, relocating assembly lines into cost competitive countries accelerated during the previous and current decade. Geneva continued to employ a significant workforce of 280 with its composition changing over time. Gone were the high volume production and assembly lines. An ever-increasing number of staff worked in product management, $\mathrm{R} \& \mathrm{D}$, industrial engineering, front-end innovation, marketing, supply chain management and sales. The Geneva site still produced the specialty components, was involved in prototyping and checked and verified new production lines set up elsewhere. ${ }^{21}$

A recurring theme of SMEs developing an ever more global manufacturing footprint was the impact on the Swiss main location. As documented, production in Switzerland, if maintained, focused on core components that were closely tied to the company's core technology. The establishment of foreign production allowed these companies to partially hedge against the continually increasing Swiss Franc in a way those producing only in Switzerland could not. However, the growing complexity of steering the global footprint also demanded a different skill base at the head office, moving from mere manufacturing to increasingly include engineering, prototyping, and development, as well as global marketing coordination. Even in cases where the mere headcount in Switzerland was maintained, it then encompassed very different professional groups.

The companies described in this section are in many ways miniglobal companies: global in market reach and coverage, and global in production footprint. They differ from the much larger multinational corporations in terms of size and focus around a single business, industry, or customer group. These companies, having grown to a size of CHF 200-500 million, would not have been able to grow to their present size without expanding their operational footprints beyond Switzerland. As a downside of this expansion, it is worth remembering a comment on colocation of manufacturing and development from the CEO of Medartis, Willy Miesch: All relevant production and process knowledge was owned by Medartis. Co-location is important to us.

\footnotetext{
${ }^{20}$ Adapted from LEM company profile.

${ }^{21}$ ibid.
} 


\section{Offshoring Production Capacity}

Only 2 of the 36 investigated companies (Datamars and u-blox) did not maintain any production capacity in Switzerland. Of those two, Datamars, the animal and textile identification company through radio-frequency identification (RFDI) chips, had gone through a deliberate offshoring decision, moving its entire production outside of Switzerland. The company was included in the research nonetheless, because at one time it did manufacture in Switzerland. Datamars maintained four production plants as of 2017. Only a few central functions, such as development, financial services, and central management, were still located in Switzerland, employing about 80 people.

In 2007, because of financial distress, Datamars decided to open a factory in Thailand. Management believed that unless they produced in a low-cost country, they could not stay competitive in the long run. Datamars made this site its sole production site for all electronic components. All third-party production in Asia, as well as the remaining production in Switzerland, was moved to Thailand, which also meant some layoffs in Switzerland. The strategy was to reduce the production costs, insource everything to achieve economies of scale and capture the value-added of the production. Production in Thailand started with 20 people and by 2018 reached an employment of 560, becoming the largest location within the Datamars group. Production was partly on standard machines and partly on specialized machines developed and refined in-house. In addition, the production process involved a certain element of implicit knowledge not easily copied. As a result of this move, Datamars was subsequently able to 'fight on price and market share' and squeeze out other small players. $^{22}$

Another big change in the Datamars production footprint came with the entry into the livestock tagging sector. Livestock identification was still dominated by ear tags with the RFDI chips molded into a plastic tag. The importance of the injection molding process for this product line triggered the company to create its own plastic molding capacity as a key process, something the company had previously wanted to avoid.

Datamars established three sites in the world where their plastic injection molding was created: Texas, Thailand and a new factory in Slovakia. Because plastic parts, such as ear tags, are more bulky than electronic components, Datamars split the production into three different locations in order to reduce shipping costs. In addition, the implantable identifiers were assembled in Spain. In the livestock business, there were also local finishing sites in all the important markets where the tags were customized according to national requirements, to be delivered to customers within 24 hours. ${ }^{23}$

u-blox represented the most extreme model of all companies, the firm never produced any of its chips or modules in Switzerland. When starting out in the late 1990s with its first commercial product, production had to be outsourced to an

\footnotetext{
${ }^{22}$ Adapted from Datamars company profile.

${ }^{23}$ ibid.
} 
international supplier in Germany because the company had no production capability. As the business grew, the company remained with its "fabless" operation, although the entire process was directed from its Swiss location where a significant number of employees took care of research and engineering coordination, marketing and sales, and administrative functions.

u-blox did not produce any chips or modules. Chips were designed by u-blox and sourced from several fabs in different Far East locations. They were shipped to an integrator company, Flextronics in Graz (Austria), for final assembly and direct shipment to OEM customers. The role of u-blox was to design all products and to ensure quality. The company had designed its own quality control methodology, testing 100 percent of output. Full traceability of manufacturers and suppliers was arranged to manage any kind of risk, political or otherwise. A dedicated supply chain unit was operating from the company's location in Thalwil, Switzerland. This unit, headed by Wyss, one of the three founders and also serving as $\mathrm{COO}$ of the company, consisted of about 30 employees. Its location in Thalwil was internally referred to as the 'Silverhouse. ${ }^{24}$

\section{Colocating Production}

Reflecting on the patterns for production footprint, the companies that find it effective to operate from a single production location are more likely to remain anchored to their Swiss production sites. The single-site companies benefitted from the colocation advantage, whereas the multisite companies partially pursued a costdriven location strategy for some of their output or, in some instances, followed their customers to provide superior delivery service. The majority of the companies found a way to combine superior production technology with differentiation of their products to justify producing from a higher cost base, such as Switzerland. The importance of colocating all activities on a single site was articulated by Felchlin, who invested CHF 20 million into a new facility to achieve this.

Due to the vision of the Felchlin founders, sufficient land reserves were available to centralize all of Felchlin's activities on a single site in Ibach (SZ). After the expansion of the cocoa bean roasting facility in 2012, Felchlin began the process of planning and constructing an additional building that allowed for the entire company to be located on a single site. To do so, Felchlin planned to vacate the old villa and adjacent buildings to move next to the Ibach site. Management considered proximity and close communication to be of special value for a small business. ${ }^{25}$

For many of the Swiss SMEs in our research sample, the colocation argument combined with exploiting the Swiss made label could compensate for the cost advantage of offshoring.

\footnotetext{
${ }^{24}$ Adapted from u-blox company profile.

${ }^{25}$ Adapted from Felchlin company profile.
} 
Open Access This chapter is licensed under the terms of the Creative Commons Attribution 4.0 International License (http://creativecommons.org/licenses/by/4.0/), which permits use, sharing, adaptation, distribution and reproduction in any medium or format, as long as you give appropriate credit to the original author(s) and the source, provide a link to the Creative Commons license and indicate if changes were made.

The images or other third party material in this chapter are included in the chapter's Creative Commons license, unless indicated otherwise in a credit line to the material. If material is not included in the chapter's Creative Commons license and your intended use is not permitted by statutory regulation or exceeds the permitted use, you will need to obtain permission directly from the copyright holder.

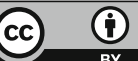

